\title{
Skin lesions on North Atlantic right whales: categories, prevalence and change in occurrence in the 1990s
}

\author{
Philip K. Hamilton*, Marilyn K. Marx \\ Edgerton Research Laboratory, New England Aquarium, Central Wharf, Boston, Massachusetts 02110, USA
}

\begin{abstract}
North Atlantic right whales Eubalaena glacialis experienced decreased reproduction and body condition in the 1990s, causing concern about the overall health of this critically endangered population. Images from a detailed photo-identification catalog of right whales were analyzed for the presence of skin lesions. Lesions were categorized as white lesions or blister lesions and each of those categories were further divided based on lesion morphology and location. Of 439 whales photo-analyzed between 1980 and 2002, white lesions were detected on 227 ind. (51.7\%) and blister lesions were found on 76 ind. (17.3\%). The majority of white lesions $(72.8 \%)$ were detected in the Bay of Fundy where their prevalence increased dramatically during the 1990 s (peaking at 40 and $41 \%$ of all identified whales in 1997 and 1999, respectively). A correlation between whale density and white lesions in the Bay of Fundy suggested that this lesion type may have been the result of a contagious agent, though the data on mother/calf pairs did not indicate transmission from mother to calf. Blister lesions appeared at low levels throughout the population over the study period. Neither lesion category was more prevalent on males or females, nor were there any differences between adults and juveniles. One white lesion type appeared exclusively on whales that had been entangled, and whose subsequent survival was in most cases questionable. This is the first detailed analysis of skin lesions in this species. Only 1 tissue sample has been previously obtained from a lesion, and thus the histology and etiology of these lesions remain unknown. Further work is needed to explore the role of disease and environmental variables in lesion prevalence.
\end{abstract}

KEY WORDS: Lesions · Skin · Epidermis · Health $\cdot$ Right whale $\cdot$ Bay of Fundy $\cdot$ Eubalaena glacialis Cetacean Resale or republication not permitted without written consent of the publisher

\section{INTRODUCTION}

Assessing the health of free-swimming cetaceans is difficult as most existing knowledge stems from data on captive or stranded individuals. In recent years, however, there have been an increasing number of studies that have used photo-identification images to assess and monitor cetacean health (Thompson \& Hammond 1992, Wilson et al. 1997, 1999, 2000, Van Bressem et al. 2003, Pettis et al. 2004). Many of these studies relied upon skin condition to provide clues about the health of the cetaceans and the ecosystem in which they live.

The North Atlantic right whale Eubalaena glacialis is one species that is particularly well suited for health studies based on photo-identification data. This spe- cies is critically endangered with a population of only 300 to 350 animals (IWC 2001) and has an extremely thorough photo-identification database, the North Atlantic Right Whale Catalog, which spans over 25 yr of dedicated study (Hamilton \& Martin 1999). In the mid-1990s researchers noticed that the skin of many right whales appeared unhealthy (lesions, excessive sloughing, and cyamid infestations [Pettis et al. 2004]). This change in skin condition coincided with a rise in the birth interval for calving females (Kraus et al. 2001) and an increase in the number of severely thin animals (Pettis et al. 2004), prompting concerns about the general health of this small population.

Skin lesions have been described primarily in odontocetes (Van Bressem et al. 1999, Gaydos et al. 2004). 
The most common and best described are tattoo and ring lesions, characteristic of poxvirus, which have been documented in a number of odontocetes including bottlenose dolphin Tursiops truncatus, Atlantic white-sided dolphin Lagenorhynchus acutus, dusky dolphin Lagenorhynchus obscurus, long-beaked common dolphin Delphinus capensis, Burmeister's porpoise Phocoena spinipinnis, and killer whale Orcinus orca (Flom \& Houk 1979, Geraci et al. 1979, Van Bressem et al. 1993, 1999, Van Bressem \& Van Waerbeek 1996). Although there are fewer studies for mysticetes, skin lesions have been described in fin whale Balaenoptera physalus (Baker 1992), bowhead whale Balaena mysticetes (Henk \& Mullan 1996), and southern right whale Eubalaena australis (Rowntree et al. 1998, Reeb 2001). Some of the proposed causes for these lesions were infectious disease (viral, fungal, or bacterial), nutritional stress leading to infection with secondary pathogens, water quality (pollution, temperature, or salinity), and predation by gulls.

The right whale has been dubbed an 'urban whale' (IWC 2001) because its primary habitats overlap with those of humans. Right whales calve along the eastern seaboard of North America, often within 1 or 2 miles of the beach. They migrate along the coast to feeding grounds in Cape Cod Bay and the Great South Channel off Massachusetts, and then into the Bay of Fundy and the East Scotian Shelf in Canadian waters. It is known that these animals are killed and injured by entanglements in fishing gear and collisions with vessels (Kraus 1990, Knowlton \& Kraus 2001, Moore et al. 2005), but the impacts of disease, water quality and other environmental factors are less understood. The study of right whale health is hindered by the rarity of necropsied animals and the advanced autolysis of most carcasses (Moore et al. 2005). A workshop on right whale reproductive health held in 2000 highlighted issues of particular concern for right whales including exposure to pollutants, impacts from toxic algal blooms, compromised health due to nutritional deficiencies, exposure to pathogens, or potential contagious diseases that could spread while the whales are concentrated in productive feeding areas (Reeves et al. 2001).

Here we report on an analysis of the prevalence of skin lesions on North Atlantic right whales from 1980 to 2002. The detailed photo-identification catalog was used to track the annual occurrence of lesions on individuals in different habitats, and to test whether lesion occurrence was correlated with age, sex, or habitat use. Because only 1 lesion sample has been collected (Moore et al. 2005), the histology and etiology of most of these lesions remain unknown. Two broad categories of skin lesions were described and the potential causes for these lesions were explored.

\section{MATERIALS AND METHODS}

Background. Right whales are individually identifiable by a combination of the callosity pattern on their heads (Payne et al. 1983, Kraus et al. 1986) and scars (Kraus 1990). A 25 yr photo-identification effort has resulted in the North Atlantic Right Whale Catalog, which has more than 30000 sightings of 459 whales (Hamilton \& Martin 1999). This catalog represents a collaborative effort of dozens of organizations that submit photographs to the New England Aquarium, which curates the collection for the North Atlantic Right Whale Consortium. The majority of the photographed sightings have been collected from 5 high-use right whale habitats: (1) waters off the southeastern U.S. (SEUS) during the winter; (2) Cape Cod and Massachusetts Bays primarily in the late winter and early spring; (3) Great South Channel east of Cape Cod, Massachusetts, in the spring (GSC); (4 \& 5) the Bay of Fundy (BOF) and Roseway Basin (RB) southeast of Nova Scotia in the summer and fall (Fig. 1). Most of the Cape Cod and Massachusetts Bay sightings came from Cape Cod Bay proper, and are referred to collectively as Cape Cod Bay (CCB) sightings for this study. The first dedicated, long-term photographic effort began in 1980 in the BOF with other habitat surveys starting after that. There has been consistent boat-based effort in the BOF, but in all other habitats the survey platform and amount of effort have varied.

In order to assess the age profiles of whales with lesions, all whales were categorized as juvenile, adult or unknown. Juveniles were defined as animals of known age that were less than 9 yr old (Hamilton et al. 1998, Kraus et al. 2001), including calves. Adults were defined in 1 of 3 ways: (1) whales of known age who were at least $9 \mathrm{yr}$ old; (2) whales of unknown age whose sighting histories spanned 8 yr or more (because they were at least 1 yr old when first sighted); and (3) any parturient female irrespective of the length of her sighting history. With the exception of these latter females, whales of unknown age and with sighting histories spanning less than $8 \mathrm{yr}$ were categorized as of unknown age.

Sex was determined in 1 of 3 ways: (1) by photographs of the genital region (Payne et al. 1983); (2) by genetic analysis of collected skin samples (Brown et al. 1994); or (3) by observation of a large whale associated with a calf over 3 sightings during a season or yr (for females only).

Photographic analysis. All photographs taken between 1980 and 2002 for each individual in the catalog were examined for the presence of skin lesions. Photographs were collected from either boat or aerial surveys and consisted primarily of color slides, although some images were black-and-white prints, color prints, 


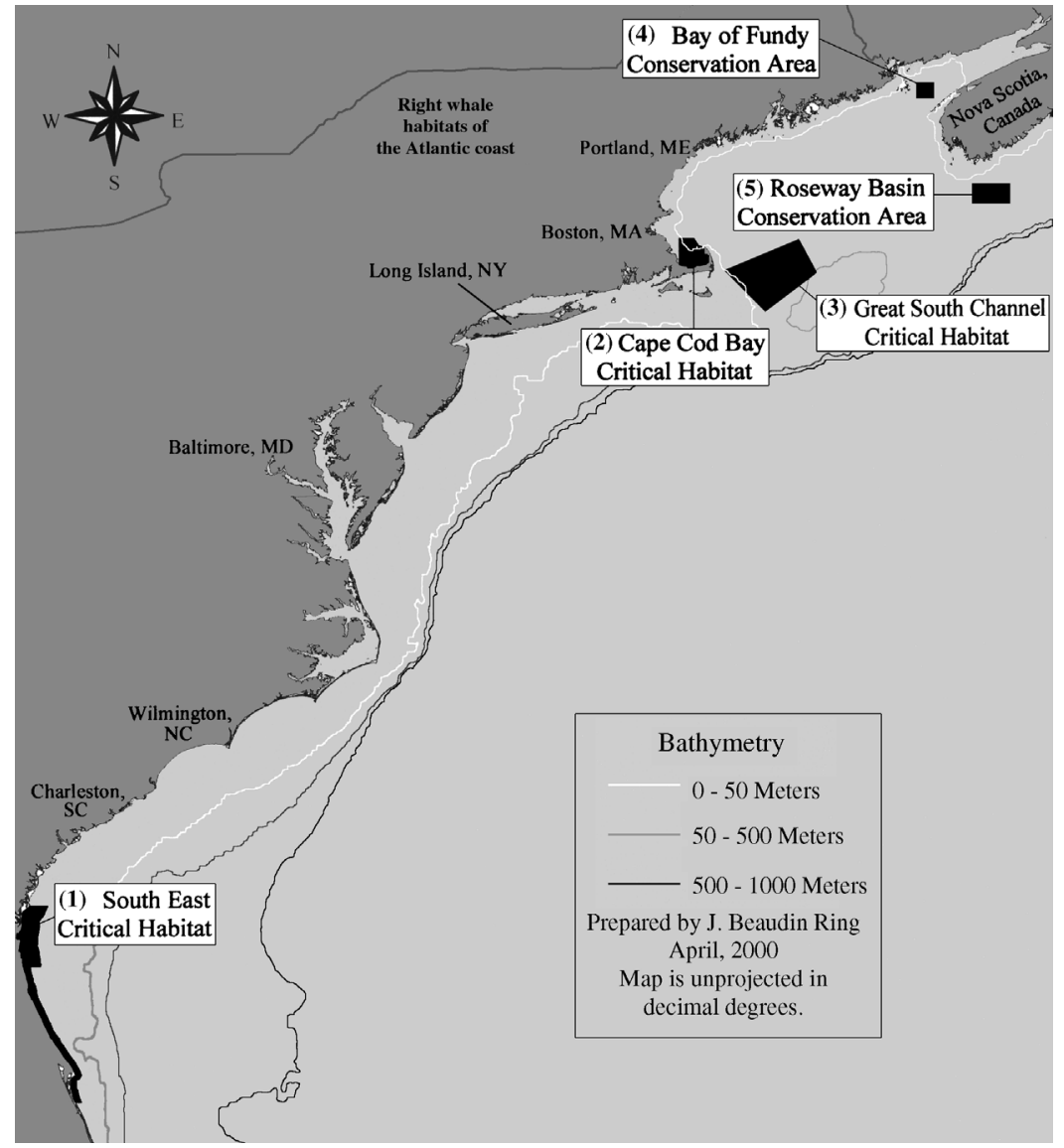

Fig. 1. Eubalaena glacialis. (1 to 5) primary habitats surveyed during this study. Nos. are referred to in the text blister-like lesions. White lesions were light in color and had indistinct boundaries. Although all white lesions were combined for reporting and analysis in this study, there appeared to be at least 4 sub-categories into which they could be separated: circular, outline, swath, and variable (Fig. 3). 'Circular lesions' were the most commonly observed lesion category. They were localized, mostly circular, vividly white lesions that generally had no raised edges or depressions. Circular lesions were found most frequently on the head and just behind the blowholes. 'Outline lesions' were a grayish, translucent color and specifically border the edge of callosity tissue, the lips, and/or the blowholes. 'Swath lesions', which were the largest white lesion type $\left(>45 \mathrm{~cm}^{2}\right)$, were found mostly on the rostrum or the neuchal region behind the blowholes. They were generally gray to white or creamy in color, though they could also have pink or yellow highlights (Fig. 3, No. 1608). 'Variable lesions' were any white lesions that did not fit into 1 of the above 3 categories. Some were translucent white and covered large areas of the back, while others had gray centers and white borders. Variable lesions had newspaper photographs, or digital images. All photographs of each individual were grouped together, ordered chronologically, and then analyzed by area and season. For example, all the photographs of a whale from the BOF from July to September 1994 were analyzed together, and the lesion information for that individual was summarized in a single record by year and geographic region. A diagram of a whale body was divided into a 21-section grid (Fig. 2) and each body section that was adequately photographed was coded for the absence or presence of lesions for each group of photographs.

Lesion definitions. Although any mark on the skin can be considered a lesion (Haldiman \& Tarpley 1993), in this study lesions referred to a class of marks that generally persisted for weeks to months and then resolved to leave a depression, a bright white scar, or no mark at all. Lesions were distinguished from skin sloughing patterns, which are light gray and change on a daily basis, and from old scars, which are white with very distinct edges and remain for the whale's lifetime.

Lesions were first broken down into 2 broad categories based upon gross morphology: white lesions and

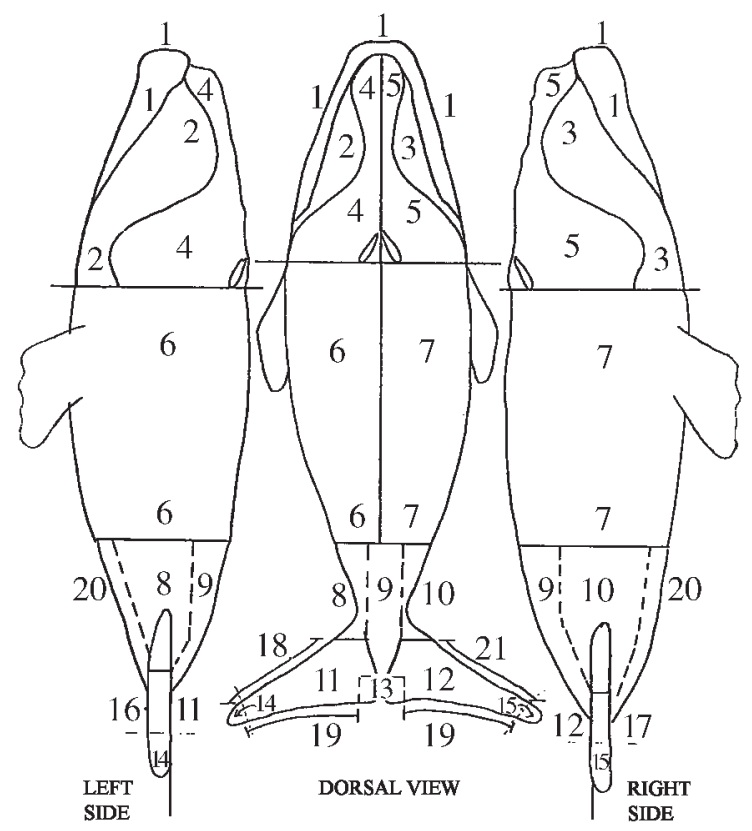

Fig. 2. Eubalaena glacialis. Body sections coded for lesion absence or presence. Body sections referred to in the text are lips $(2,3)$, rostrum $(4,5)$, back $(6,7)$, and peduncle $(8-10,20)$ 
No. 2705- 2 1/2 yr old male, circular lesion

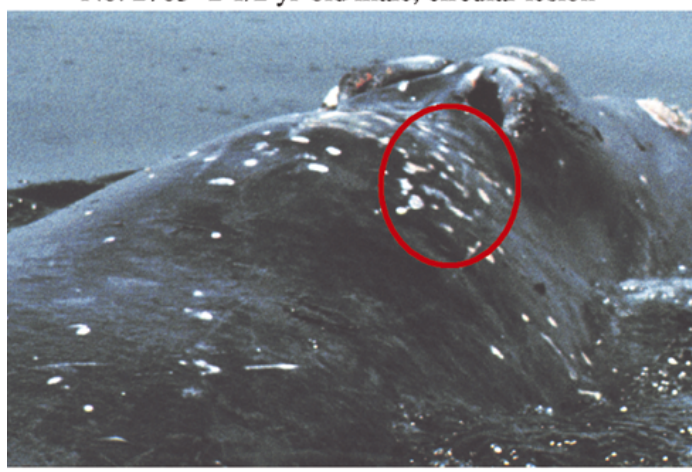

No. 2212- 6 yr old male, outline and circular lesions

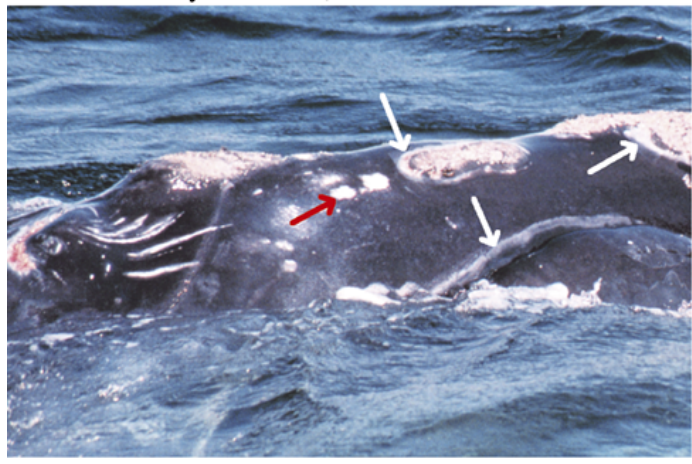

No. 1907- 2 yr old female, swath lesion

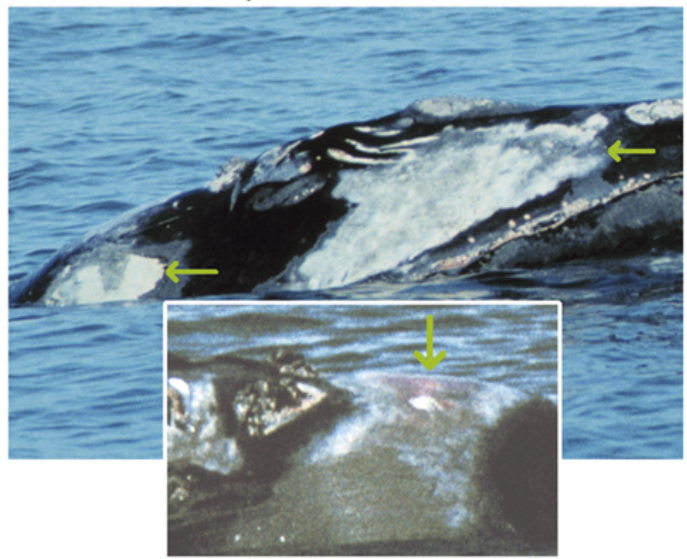

No. 2303- 8 yr old male- circular, outline and variable lesions

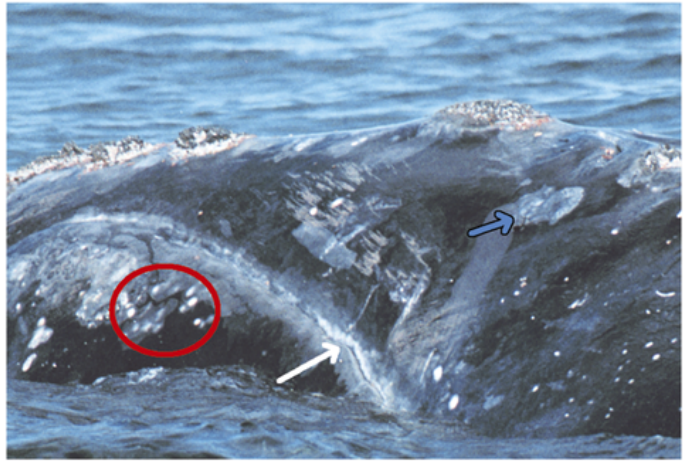

No. 2750 - $21 / 2$ yr old female, outline and circular lesions

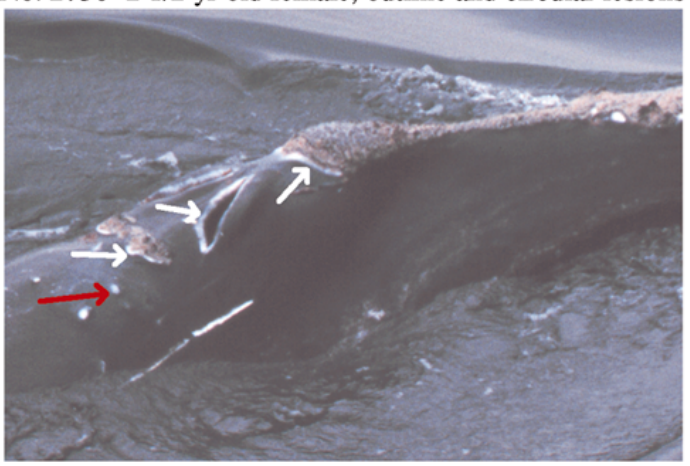

No. 1608- 18 yr old female, swath lesion

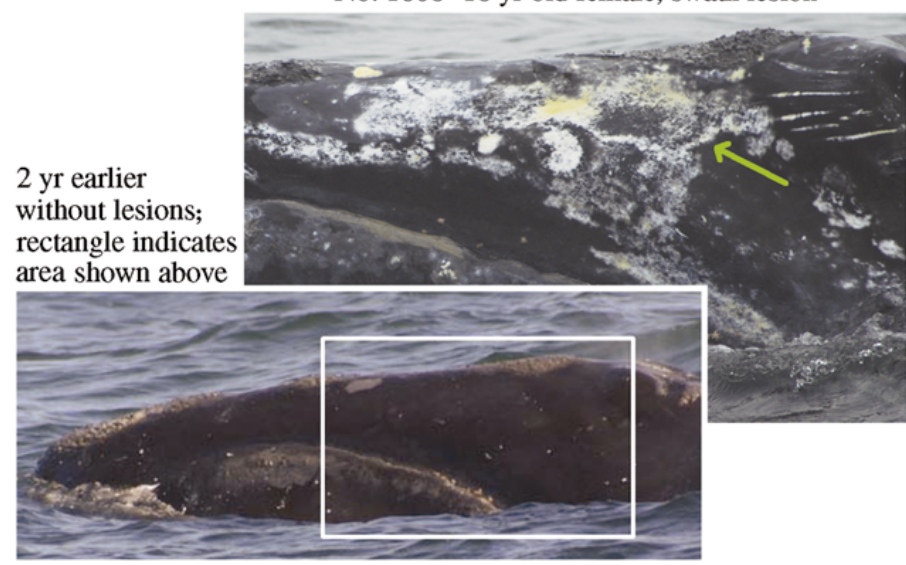

No. 1332- 14+ yr old male, circular and variable lesions
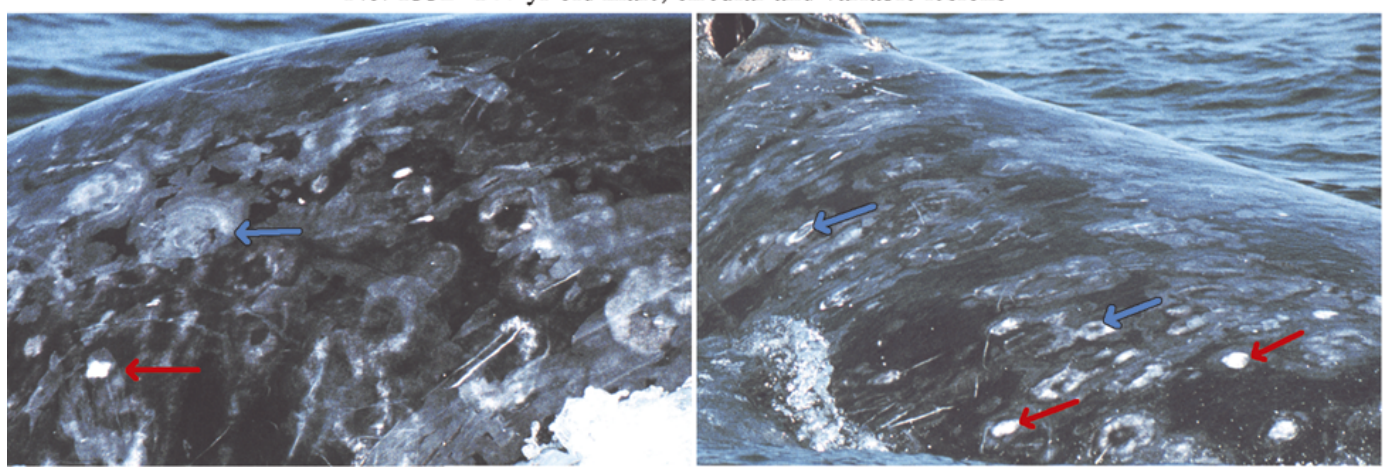

Fig. 3. Eubalaena glacialis. White lesions. Whale catalog no., age at time of photograph, and sex are provided above each example; red: circular lesions, white: outline lesions, green: swath lesions, blue: variable lesions 
inconsistent shapes and could be found anywhere on the body, though they appeared to be more common on the back or peduncle.

These 4 lesion types did not appear to be different stages of a single lesion (i.e. circular lesions do not transition into swath lesions) and a whale could have more than 1 lesion type concurrently. Outline lesions occurred concurrently with either circular lesions or swath lesions, but swath and circular lesions rarely cooccurred. Variable lesions could co-occur with both circular and outline white lesions. If future information indicates that these 4 lesion types have different causes, then additional analyses will be conducted.

Without histopathology, it is unknown whether the blister-like lesions are true blisters, but they were referred to as blister lesions in this study based on their appearance. Blister lesions were separated into 2 subcategories. 'Small blisters' refers to blister-like vesicles that were multi-focal, usually clustered, and were primarily on the back. 'Craterous eruptions' refers to single localized craters that are $\sim 10$ to $15 \mathrm{~cm}$ diameter. They have raised edges, a central protrusion, and are seen on the back or peduncle (Fig. 4). Craterous eruptions can develop into ulcerative lesions with a papillomatous core (Moore et al. 2005) (Fig. 4, No. 1014). Both the small blisters and the craterous eruptions can result in craters and they were therefore analyzed as 1 broad category.

White and blister lesions were the focus of this investigation. However, during the analysis, another lesion type was discovered. An image of these lesions, which were referred to as 'tattoo-like lesions', is provided here for comparison (Fig. 5), but epidemiological data on these lesions were not analyzed. Tattoo-like lesions were gray and plaque-like with raised edges, and seemed to occur in broad areas on the back.

Statistical analysis. The age class and the sex of whales with and without lesions were tested with a Fisher's exact test using SPSS statistical software (version 11.5). For each year, the number of adults and
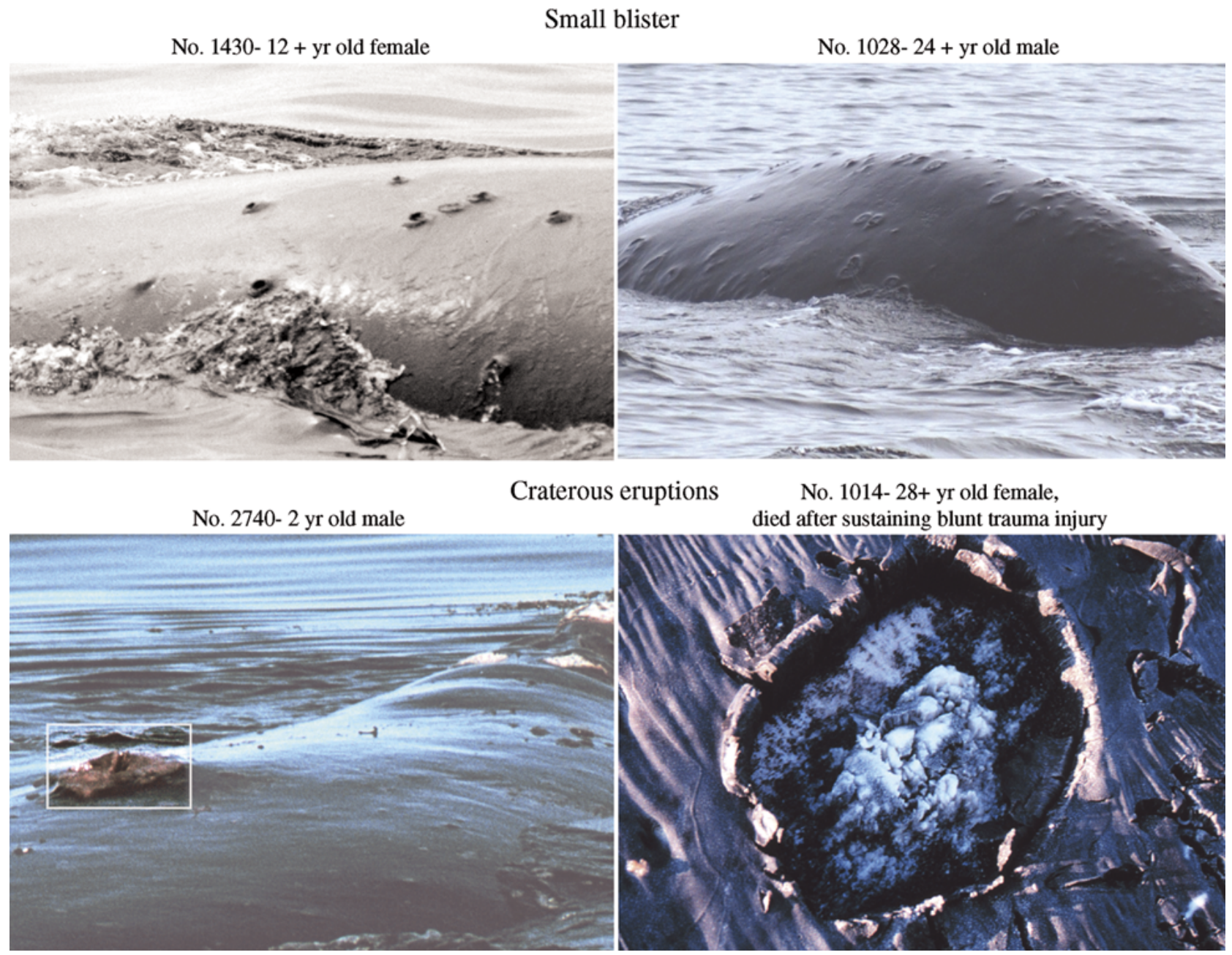

Craterous eruptions

No. 1014- 28+ yr old female, died after sustaining blunt trauma injury

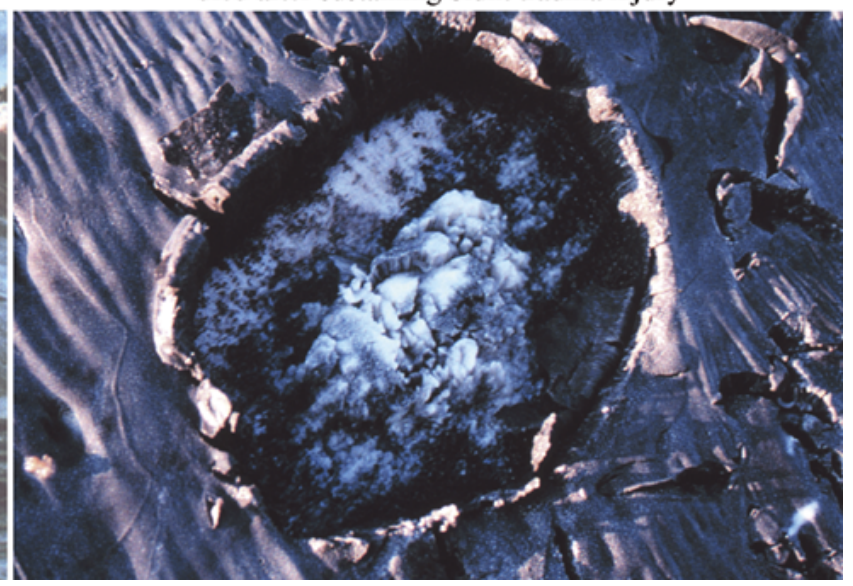

Fig. 4. Eubalaena glacialis. Blister lesions. Whale catalog no., age and sex at time of photograph are provided above each example 
No. 1033-24+ yr old male, tattoo-like lesions

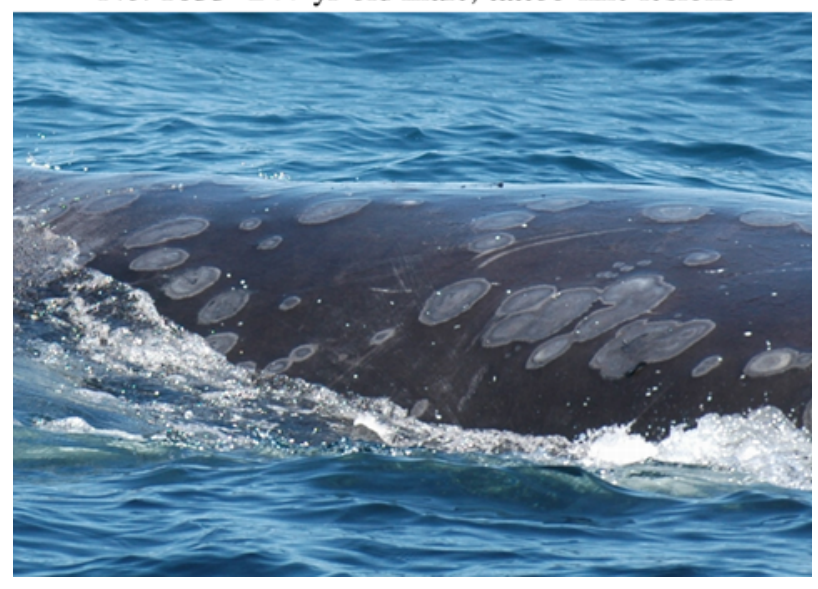

Fig. 5. Eubalaena glacialis. Tatoo-like lesions. Whale catalog no., age at time of photograph and sex are provided

juveniles documented with their first lesions were compared to the numbers with no lesions. This test detected yearly differences while correcting for the total number of whales identified in the area. A second $2 \times 2$ contingency table pooled the data from all years The yearly numbers from the first analysis were summed and compared to each other for all years combined. This test took into account changes in the number of whales identified over the years and provided a larger sample size to detect differences among age classes. These same 2 tests were then applied to the data for males and females. For all statistical analyses of white lesions, only the first occurrence of white lesions on the head and lip in the BOF were used. Because photographs of the whale's head are necessary for photo-identification, lesions on the head could be normalized by the number of whales identified. Further, using data only from the first occurrence of a lesion on a whale removes potential confusion because new lesions on the same whale in subsequent years could be caused by 1 initial disease exposure. Lastly, limiting data to the first occurrence of a lesion eliminated issues of non-independence of observations when data are pooled across years.

One potential cause of skin lesions is contagious disease, which is more likely to spread when many animals are aggregated (Van Bressem et al. 1999). The relationship between whale density and lesions was tested using data from white-lesion occurrence in the $\mathrm{BOF}$, where the majority of that lesion type was detected. The percentage of whales identified in the bay that had lesions on their heads was calculated from 1980 to 2002. That percentage was ranked and tested against a ranked value for the exposure risk that year. As a crude estimate of exposure risk, a 2 wk rolling count of all whales identified in the bay was calculated for each year. For each Monday of the field season, the total number of individuals identified from the previous Monday through the following Sunday was calculated (1 ind. could not be counted more than once for each 14 day period), and the largest of those 2 wk values for the season was used as a measure of exposure risk. This method represented exposure risk better than the total identified for the season because a large seasonal total could result from a large amount of turnover and relatively few whales in the bay at any one time. A correlation between these 2 ranked values was tested using Kendall's coefficient of rank correlation (Sokal \& Rohlf 1995, p 595). To further explore the potential of contagion, all mothers whose calves were photo-identified were separated into those with white lesions and those without. The number of calves with white lesions that nursed from mothers with lesions was compared to those that nursed from mothers without white lesions using a Fisher's exact test.

Lastly, a Mantel-Haenszel test (Sokal \& Rohlf 1995, p 764) in SPSS was used to determine whether blister and white lesions occurred in $\mathrm{CCB}$ and the BOF in similar proportions.

\section{RESULTS}

A total of 25903 sightings of 439 whales between 1980 and 2002 were reviewed and their lesion histories summarized into 6280 records by habitat and year. Of the 439 whales analyzed, 227 (51.7\%) exhibited white lesions somewhere on their bodies and 76 (17.3\%) had blister lesions.

\section{White lesions}

White lesions progressed in various ways. Some formed in a matter of days, and others appeared to take months to fully manifest (Fig. 6a,b). Once manifested, some lesions disappeared altogether, some resolved into a scar that was smaller and whiter than the initial lesion, and some remained relatively unchanged over several years.

The majority of white lesions occurred on the head, defined here as the rostrum and lips combined (lips $24.4 \%$, rostrum $43.5 \%$, back $26.0 \%$, peduncle $1.6 \%$, other $4.5 \%$ ). To correct for sighting effort and changes in whale abundance each year, only whales with lesions on the head were analyzed further. This reduced the sample from 584 records of 227 whales to 470 records of 192 whales. Of the 470 records of white lesions on the head, more than $70 \%$ occurred in the BOF (BOF 72.8\%, $\mathrm{n}=342$; CCB $7.4 \%, \mathrm{n}=35$; GSC $9.6 \%, \mathrm{n}=45$; RB $4.0 \%, \mathrm{n}=19$; other $6.2 \%, \mathrm{n}=29$ ). 
February 1991 lesion beginning to form

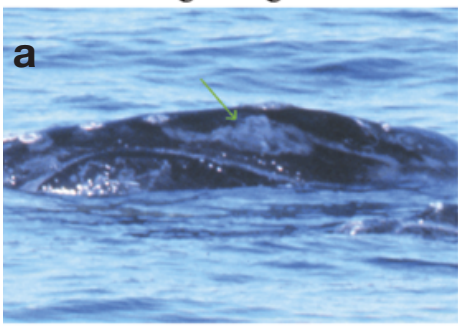

October 1997- no lesion

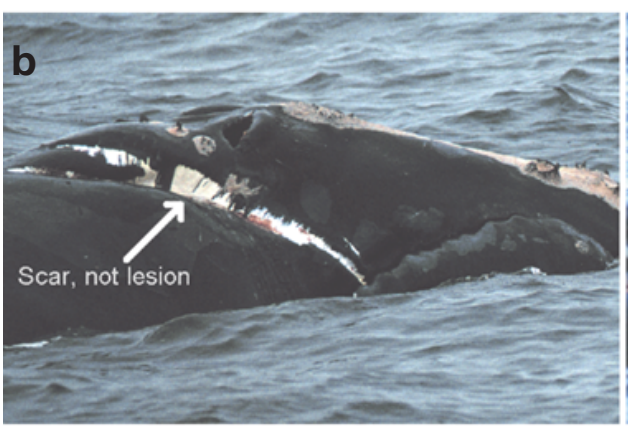

August 5, 1999- Crater begins to form

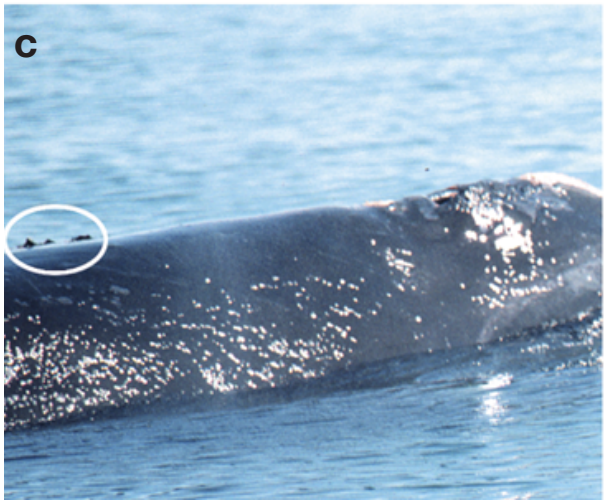

August 1991both swath and outline lesions

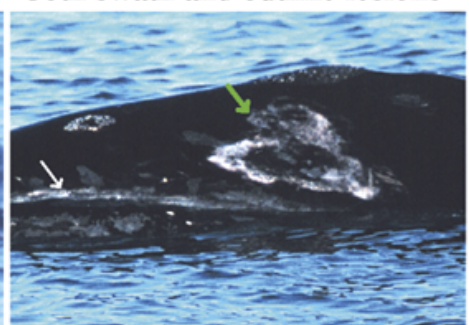

May 1999- lesion begins to form

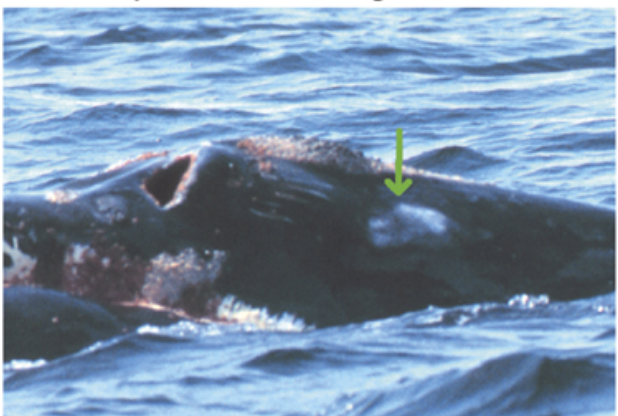

September 27, 1999- lesion fully erupted

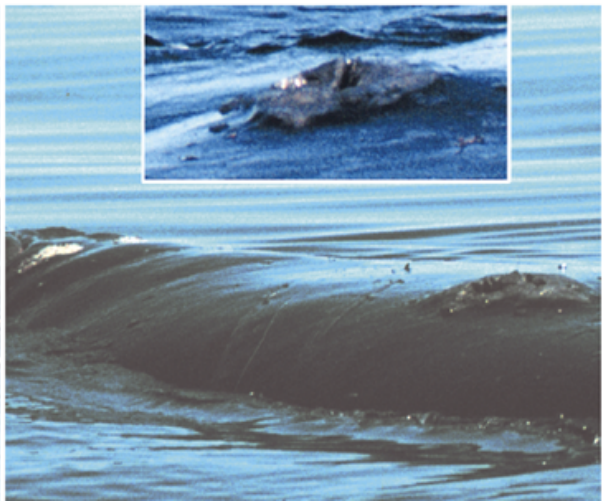

September 1991

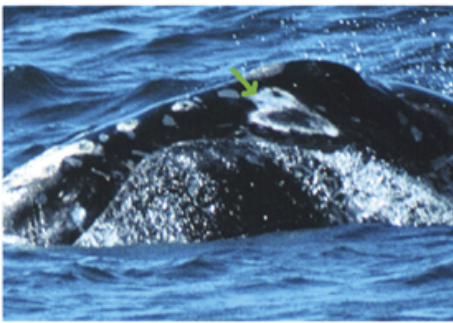

February 1992

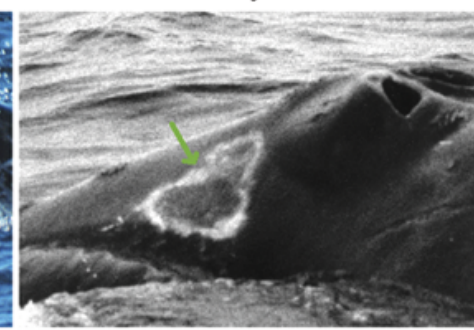

October 1999

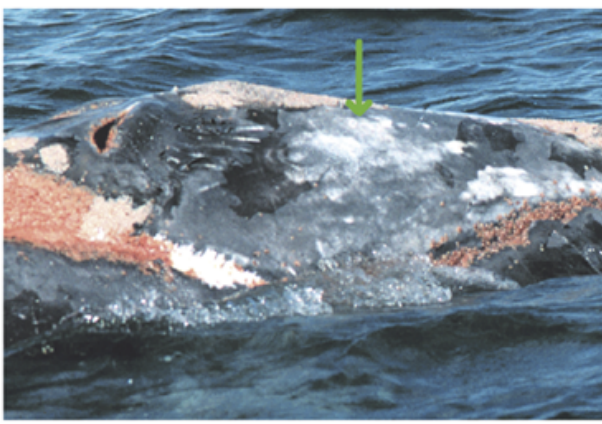

April 21, 2003- the resulting divot with orange cyamids remains

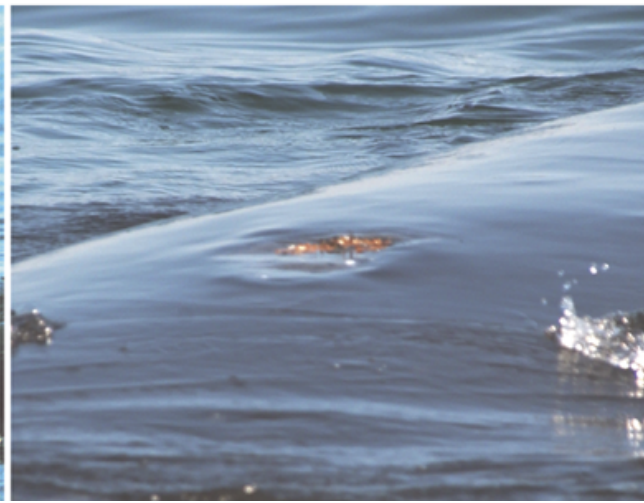

Fig. 6. Eubalaena glacialis. Progression of swath lesions (a,b) and a blister lesion (c). (a) Swath lesion on 10 yr old female 'Stars' no. 1163 ; (b) swath lesion on 13+ yr old male, no. 1621 (scar behind and below right blowhole is from an entanglement and is not the lesion in question; this scar was covered with orange cyamids in October 1999); (c) craterous eruption (blister lesion) on 2.5 yr old male, no. 2740

Because of the large percentage of white lesions observed in the BOF, this subset of data (342 records of 165 whales) was used for all subsequent analyses. By focusing on data from 1 habitat, confounding factors due to differences in habitat, time of year, survey effort, and survey platform were removed.

The occurrence of white lesions in the BOF increased dramatically in the 1990s. Lesion prevalence exhibited a fluctuating pattern that has been consistent since 1992, peaking at $40 \%$ in 1997 and $41 \%$ in 1999 (Fig. 7). Data for the first occurrences of white lesions were analyzed between sex and age classes (because there were no records of lesions in some age and sex categories prior to 1993, only data from 1993 to 2002 were used.) There was no difference between genders either annually or across all years (66 females, 94 males, Fisher's exact test $\mathrm{p}=1.00$ ). An average of $10 \%$ of identified males and $10 \%$ of identified females were seen with white skin lesions (range for males was 2 to $29.3 \%$; range for females 2.7 to $24.7 \%$ ). Similarly, age class did not appear to be a factor in lesion occurrence, with $11.9 \%$ of all available adults and $10.9 \%$ of all juveniles having white lesions (100 adults, 43 juveniles, Fisher's exact test $\mathrm{p}=0.51$, range for adults 2.8 to $26.6 \%$ and for juveniles 2.1 to $34.6 \%$ ).

Calves that nursed from mothers with lesions were no more likely to have lesions than other calves. The first record of a nursing female with white lesions was 


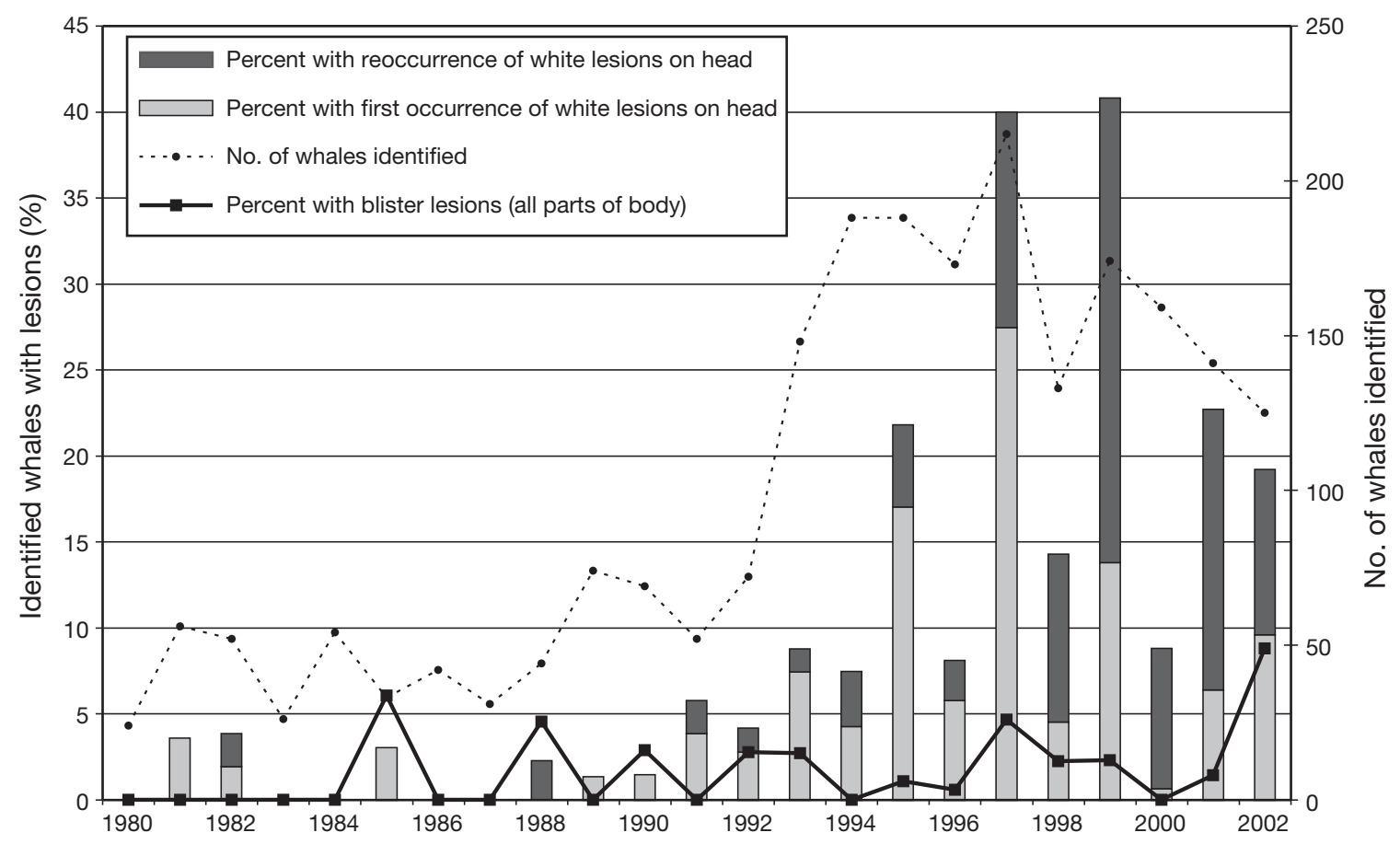

Fig. 7. Eubalaena glacialis. Occurrence of lesions in the Bay of Fundy (BOF) from 1980 to 2002

in 1991. From 1991 to 2002, there were 15 photoidentified calves that nursed from mothers with lesions and only 1 of those calves, or $6.7 \%$ of the total, exhibited lesions. This was not significantly different from the number of calves with lesions that nursed from mothers without lesions during the same time period ( 5 out of 78 or $5.5 \%, 1$-sided Fisher's exact test $p=0.641$ ).

Finally, the percentage of whales with lesions on the head was tested against the exposure index (the maximum number of ind. identified in a 2 wk period) by yr using Kendall's coefficient of rank correlation $(\tau)$. Because there were several 0 values for lesions in years prior to 1988, and ranking more than one tied value is problematic, only data from 1988 to 2002 were used. This 1-tailed test, which tests the hypothesis that increased exposure would result in increased lesion prevalence, showed a significant positive correlation between the 2 variables $(\tau=0.524, \mathrm{n}=15, \mathrm{p}=0.003)$.

Although the 4 categories of white lesions were combined for these analyses, swath lesions were both rare and severe enough to stand out. There were 6 whales with swath lesions (4 females: ages 1, 2, 10 and 14+ yr; 2 males: ages $8+$ and $21+$ yr. Note: the 118 yr female with swath lesions in Fig. 3 was observed in 2004 and was not included in the analysis). All 6 whales with swath lesions had either been entangled previously or were entangled in fishing gear when the lesion appeared. Four of those 6 are either known to have died or suspected to be dead (because of their condition at last sighting and the length of time since they were last sighted). Further, the body condition of 4 of the 6 whales with swath lesions has been assessed by Pettis et al. (2004), and 3 of the 4 were severely thin at the time the lesions were apparent.

\section{Blister lesions}

Blister lesions showed a different temporal and geographic pattern to the white lesions. There were 100 records of 76 whales with blister lesions $(17.3 \%$ of whales analyzed). Blisters occurred primarily on the back (lips $0.6 \%$, rostrum $16.2 \%$, back $71.4 \%$, peduncle $4.5 \%$, other $7.3 \%$ ), and mostly resolved to a small raised scar or a cyamid-filled divot (Fig. 6c). Blister lesions were equally common in both $\mathrm{CCB}$ and the BOF (BOF 45.0\%, $\mathrm{n}=45$; $\mathrm{CCB} 42.0 \%, \mathrm{n}=42$; GSC $7.0 \%, \mathrm{n}=7$; RB $2.0 \%, \mathrm{n}=2$; other $4.0 \%, \mathrm{n}=4$ ). There was a significant difference in the geographic occurrence of blister lesions compared to white lesions (BOF: 342 whales with white lesions, 45 with blisters; CCB: 35 whales with white lesions, 42 with blisters; $\left.\chi^{2}{ }_{\mathrm{MH}}=74.695, \mathrm{p}=0.00\right)$.

It was more difficult to accurately correct blister lesion occurrence for sighting effort and whale distribution. Although some portion of the back is visible in most photo-identification images, it is generally not visible in its entirety. Even with this limitation, the percent of identified whales with blisters was still the best available way to correct for effort. This percent- 
age did not show any noticeable temporal pattern or increase (Fig. 7). The Fisher's exact test was applied to data from $\mathrm{CCB}$ and the BOF for sex and age class (because there were no records of blisters in some age and sex categories prior to 1996, only data from 1996 to 2002 were used.) Similar to results for the white lesions, both sexes and age classes were equally likely to have blister lesions. There was no difference between genders either annually or across all years (26 female, 24 male, Fisher's exact test $p=0.25$ ). Likewise, adults and juveniles experienced a similar frequency of blister lesions (36 adults, 11 juveniles, Fisher's exact test $\mathrm{p}=0.74$ ), though some annual differences were observed. Significantly more adults had blister lesions in 1996 (10\% of adults $(n=12)$ versus $0 \%$ of juveniles, Fisher's exact test $p=0.04$ ). In other years, the percentage of juveniles with blisters was greater than the percentage of adults, but this was never significant.

\section{DISCUSSION}

Although skin lesions on North Atlantic right whales have been discussed briefly in 2 previous studies (Pettis et al. 2004, Moore et al. 2005), this is the first analysis of their prevalence and detailed description of their morphology. The geographic and temporal distribution of the 2 lesion types suggests that they have different etiologies or co-factors. White lesions are more common than blister lesions and were detected primarily in the BOF. The peaks in white lesion occurrence in the late 1990s resembles that of a disease event passing through the population (Fig. 7), whereas the pattern of blister lesions implies a more chronic condition that affects a small portion of the population on a regular basis.

The difficulty of collecting biopsies from freeswimming whales (especially from the head), the rarity of carcasses, and the rapid tissue autolysis in available carcasses makes the sampling of lesions from this population difficult. Data from histopathology and electron microscopy are available for only 1 craterous eruption from a dead female whale in 1999 (Moore et al. 2005). The histology showed 'vacuolation and hydropic degeneration of keratinocytes, ulceration, papilliform proliferation, loss of pigment and perivascular infiltration of acute and chronic inflammatory cells' (Moore et al. 2005). Preliminary electron microscopic studies did not reveal an etiological agent (Reeves et al. 2001). This lesion had not been detected on this animal (No. 1014, 'Staccato') while she was alive, and the necropsy discovered evidence of chronic inflammation in the dermis and a partially healed fractured jaw, likely the result of a ship strike.
There were only 2 other cases of craterous eruptions in the analysis, both of which also occurred in the late 1990s (1997 and 1999). The lesions appeared similar to those on Staccato, but both resolved into small divots and the individuals currently appear to be healthy. A number of whales in the population have divots of unknown origin on their backs that resemble these resolved lesions (Fig. 6c, far right), and it is possible that some of them are the remains of past craterous eruptions. It is unknown whether there is any relationship between small blister lesions and craterous eruptions. Staccato was documented with small blister lesions on her back in 1996, 3 yr prior to her death, and then with craterous eruptions on her ventral peduncle after her death (1999). It is unknown whether small blisters or craterous eruptions were also present on her peduncle in 1996, as this area was not photographed at the time. The other 2 whales with craterous eruptions had never been seen with small blister lesions.

The swath lesion was the least common of the white lesions. The large size of the lesions, their correlation with entanglements, the thinness of the affected animals, and the known or suspected mortality of those animals with swath lesions are all clear indicators that this type of lesion is cause for concern. However, 1 of the 6 whales with swath lesions appeared to be more resilient than the others. This male, No. 1621, exhibited swath lesions in 1994 and 1999. Catalog No. 1621 exhibited swath lesions in 1994 and 1999. In both cases Pettis et al. (2004) determined his body condition to be intermediate, and in both cases the swath lesion resolved to black, healthy skin (Fig. 6b, image from October 1997). This animal's ability to recover from swath lesions seems to be unique and may provide some future clues about susceptibility. For example, whales in this population have very low levels of genetic diversity (Schaeff et al. 1997, Malick et al. 2000, Waldick et al. 2002) and some may be more resistant to disease than others due to sequence differences within the Major Histocompatibility Complex (MHC) (e.g. Paterson et al. 1998).

Some of the lesions on right whales resemble those described in other species. The tattoo-like lesions resemble tattoo lesions seen on bottlenose (Tursiops truncatus) (Van Bressem et al. 2003) and other dolphins (Van Bressem \& Van Waerbeek 1996). Circular white lesions are similar to white or cream lesions described in bottlenose dolphins by Wilson et al. (1997), and also to some of the ring lesions described in the same population of dolphins by Thompson \& Hammond (1992). The outline white lesions look somewhat like the white fin fringe on Tursiops' dorsal fins (Wilson et al. 1997), and the small blister lesions resemble the vesicular skin lesions caused by calcivirus 
(Smith et al. 1983), which can be acquired through contaminated water. Good reviews of some of the infectious disease threats to cetaceans are provided by Van Bressem et al. (1999) and Gaydos et al. (2004).

The evidence for a contagious disease in this right whale population is inconsistent. Contagion is likely to spread via aerosol, feces, or direct body contact (e.g. Black 1991). North Atlantic right whales changed their distribution in 1993 (IWC 2001) when the number of whales utilizing the BOF increased 2- to 3-fold (Fig. 7). This habitat shift clearly increased the density of animals in the bay, and the correlation between the exposure risk and white lesion prevalence supports the hypothesis of a contagious disease. If the lesions were spread by contact, however, one might expect males to be more susceptible. Males are significantly more social than females (Hamilton 2002), largely because of their prominence in surface active groups (SAGs). SAGs are generally composed of a single female and many males rolling and touching (Kraus \& Hatch 2001). These groups can involve as many as 45 males in the summer and fall. That females are equally likely to be seen with white lesions as males does not appear to support the hypothesis that the condition is the result of a contagious disease. Furthermore, calves nursing from mothers with lesions were no more likely to develop lesions than calves nursing from mothers without lesions, suggesting either that the condition is not contagious or antibodies for the disease are passed on through the mother's milk (Van Bressem \& Van Waerebeek 1996).

Besides contagious disease, there are several environmental factors in the BOF that could impact the occurrence of white lesions. For example, a parasitology study of right whale feces collected in the bay found right whales to have the highest prevalence of infection with potentially pathogenic protozoa of any marine mammal yet examined (Hughes-Hanks et al. 2005). Also, Durbin et al. (2002) found evidence that right whales in the bay are chronically exposed to a neurotoxin from the dinoflagellate Alexandrium fundyense (responsible for paralytic shellfish poisoning), which they ingest through their primary prey Calanus finmarchicus. Sublethal effects of pathogens and biotoxins could possibly weaken a whale's immune system and allow secondary infections to manifest. Wilson et al. (1999) found that the severity and prevalence of lesions in bottlenose dolphins (Tursiops truncatus) was correlated more with low water temperature and salinity than with levels of contaminants. The authors also found a significant correlation with UV-B exposure and lesion severity, and UV-B radiation is known to affect the immune system in other mammals including humans (Morison 1989). Other environmental factors could include waterborne exposure to chemicals that affect skin condition, or lack of specific nutrients needed for skin integrity. For example, Beckmen et al. (1997) found skin lesions correlated with vitamin A deficiency in northern elephant seals (Mirounga angustirostris). Future studies should examine the relationship of skin lesions with these and other environmental factors.

Several factors may have affected the analysis of these lesions. Skin lesions are more difficult to detect with aerial photographs than with shipboard photographs. Since some habitats are primarily surveyed by aircraft (CCB after 1997, and most surveys from SEUS and GSC), whales in these habitats may appear to have few lesions simply as an artifact of photographic quality. An exploration of the impact of the transition of CCB surveys from shipboard to aerial in 1998 suggested that the detection of blister lesions was particularly hampered. Also, the apparent lack of white lesions in CCB may be caused, in part, by the difficulty of obtaining high quality photographs there, regardless of the platform type. Whales in CCB tend to dive for longer periods, be more difficult to approach, and have unpredictable underwater movements. Also, surveys there occur in the winter and early spring when good weather conditions are rare and the light available for photography is poor. Combined, these factors hamper the number of high quality images that can be collected in $\mathrm{CCB}$, and in turn affect the ability to reliably assess the presence of skin lesions. Lastly, the researchers who coded the images changed part way through the time series, which may have influenced the analysis. One researcher analyzed the images from 1980 through 1995, and a second analyzed all images after that. The first researcher periodically reviewed the second's coding to maintain consistency, but it is likely that they coded some skin marks differently. However, both were conservative in coding a mark as a lesion, and therefore any bias would have resulted in an underestimation of lesions.

The North Atlantic right whale population showed several signs of ill health in the 1990s. Right whales had an increase in their birth interval from a mean of $3.67 \mathrm{yr}$ prior to 1993 to over $5 \mathrm{yr}$ between 1993 and 2000 (Kraus et al. 2001). Although the cause of this increase was unknown, the authors suggested inbreeding, pollutant effects, and food limitations as potential factors. During this same period, Pettis et al. (2004) used a technique for visual health assessment based on photographs to categorize body condition, and reported that a number of animals became severely thin. The story of the health of this population became even grimmer when the pattern of white skin lesion prevalence was added. Whether the factors that caused these changes (increased birth interval, thin 
body condition, lesions) proved fatal for some right whales is unknown. Pettis et al. (2004) found evidence that whales with poor skin condition experienced lower survivorship. In contrast, we found that most of the whales with lesions (other than those with swath lesions) recovered completely or survived to experience a re-occurrence. Knowlton \& Kraus (2001) found no increase in mortalities of unknown cause during peak lesion years, but these data are not conclusive. Any animal whose condition had deteriorated due to chronic poor health would have reduced blubber stores and likely sink upon death, and that death would go undetected (Knowlton \& Kraus 2001, Moore et al. 2005).

The occurrence of white lesions appears to represent an episodic event whereas blister lesions seem to reflect a more constant condition. There is no evidence that any of the lesions, except possibly swath lesions, are indicative of a fatal condition, but they may represent a sublethal condition that could impact or reflect overall health in some way. Further study of right whale skin lesions is necessary and should include an examination of the relationship between environmental variables (such as salinity and water temperature) and lesion occurrence, particularly in the BOF in the late 1990s. Other lines of investigation should include the collection of feces from animals with lesions to look for indicators of generalized stress and pathogens, and increased efforts to collect tissue samples from both live and dead animals for histopathology. Lastly, samples from the exhalations or blows of live whales with lesions could be cultured to further test the hypothesis of a contagious disease. The presence of skin lesions is a clear indicator of compromised right whale health and may reflect declining habitat quality - a concern for this critically endangered whale and perhaps for the health of coastal ecosystems.

Acknowledgements. It is with profound gratitude that we acknowledge the contribution of H. M. Pettis to this endeavor. Her enthusiasm, meticulous attention to detail, patience and good humor were greatly appreciated throughout this project. Also, thanks to R. M. Rolland for her invaluable input including clarification of the physiological processes and appropriate terminology for disease, recommendations for the treatment of the data, and review of the manuscript. M. J. Moore and J. R. Roman provided additional editorial comments. These data would not be available without the leadership of S. D. Kraus and the collaborative nature of the North Atlantic Right Whale Consortium. Many individuals and organizations contributed data for this analysis; we particularly thank the Provincetown Center for Coastal Studies in Provincetown, MA, whose survey effort detected nearly half the blister lesions described here. A dedicated crew of people did the photographic matching for the catalog, including J. N. Ciano, L. A. Conger, M. J. Crone, A. K. Knowlton, H. M. Pettis, B. P. Pike, and S. M. Martin. Maintenance of the North Atlantic Right Whale Catalog is funded annually by NOAA Fisheries.

\section{LITERATURE CITED}

Baker JK (1992) Skin disease in wild cetaceans from British waters. Aquat Mamm. 18:27-32

Beckmen KB, Lowenstein LJ, Newman J, Hill J, Hanni K, Gerber J (1997) Clinical and pathological characterization of northern elephants seal skin disease. J Wildl Dis 33: $438-449$

Black F (1991) Epidemiology of Paramyxoviridae. In: Kingsbury DW (ed) The Paramyxoviruses. Plenum Press, New York

Brown MW, Kraus SD, Gaskin DE, White BN (1994) Sexual composition and analysis of reproductive females in the North Atlantic right whale, Eubalaena glacialis, population. Mar Mamm Sci 10:253-265

Durbin E, Teegarden G, Campbell R, Cembella A, Baumgartner MF, Mate B (2002) North Atlantic right whales, Eubalaena glacialis, exposed to paralytic shellfish poisoning (PSP) toxins via a zooplankton vector, Calanus finmarchicus. Harmful Algae 1:243-251

Flom JO, Houk EJ (1979) Morphologic evidence of poxvirus in 'tattoo' lesions from captive bottlenosed dolphins. J Wildl Dis 15:593-596

Gaydos JK, Balcomb KC, Osborne RW, Dierauf L (2004) Evaluating potential infectious disease threats for southern resident killer whales, Orcinus orca: a model for endangered species. Biol Conserv 177:253-262

Geraci JR, Hicks BD, St Aubin DJ (1979) Dolphin pox: a skin disease of cetaceans. Can J Comp Med 43:399-404

Haldiman JT, Tarpley RJ (1993) Anatomy and physiology. In: Burns JJ, Montague JJ, Cowles CJ (eds) The bowhead whale, Spec Publ No. 2. The Society for Marine Mammalogy, Lawrence

Hamilton PK (2002) Associations among North Atlantic right whales. MSc thesis, University of Massachusetts, Boston

Hamilton PK, Martin SM (1999) A catalog of identified right whales from the North Atlantic: 1935-1997. New England Aquarium, Boston

Hamilton PK, Knowlton AR, Marx MK, Kraus SD (1998). Age structure and longevity in North Atlantic right whales (Eubalaena glacialis) and their relation to reproduction. Mar Ecol Prog Ser 171:285-292

Henk WG, Mullan DL (1996) Common epidermal lesions of the bowhead whale, Balaena mysticetes. Scanning Microsc 10:905-916

Hughes-Hanks JM, Rickard LG, Panuska C, Saucier JR, O'Hara TM, Dehn L, Rolland RM (2005) Prevalence of Cryptosporidium spp. and Giardia spp. in five marine mammal species. J Parasitol 91:1225-1228

IWC (International Whaling Commission) (2001) Report of the workshop on status and trends of western North Atlantic right whales. J Cetacean Res Manage (Spec Issue 2): 61-87

Knowlton AR, Kraus SD (2001) Mortality and serious injury of northern right whales (Eubalaena glacialis) in the western North Atlantic Ocean. J Cetacean Res Manage (Spec Issue 2):193-208

Kraus SD (1990) Rates and potential causes of mortality in the north Atlantic right whales (Eubalaena glacialis). Mar Mamm Sci 6:278-291

Kraus SD, Hatch JJ (2001) Mating strategies in the North Atlantic right whale (Eubalaena glacialis ). J Cetacean Res Manage (Spec Issue 2):237-244

Kraus SD, Moore KE, Price CE, Crone MJ, Watkins WA, Winn HE, Prescott JH (1986) The use of photographs to identify individual North Atlantic right whales (Eubalaena glacialis). Rep IWC (Spec Issue 10):145-151 
Kraus SD, Hamilton PK, Kenney RD, Knowlton AR, Slay CK (2001) Status and trends in reproduction of the North Atlantic right whale. J Cetacean Res Manage (Spec Issue 2):231-236

Malik S, Brown MW, Kraus SD, White BN (2000) Analysis of mitochondrial DNA diversity within and between North and South Atlantic right whales. Mar Mamm Sci 16: $545-558$

Moore MJ, Knowlton AR, Kraus SD, McLellan WA, Bonde RK (2005) Morphometry, gross morphology and available histopathology in North Atlantic right whale (Eubalaena glacialis) mortalities (1970-2002). J Cetacean Res Manage 6:199-214

Morison WL (1989) Effects of ultraviolet radiation on the immune system in humans. Photochem Photobiol 50: 515-524

Paterson S, Wilson K, Pemberton JM (1998) Major histocompatibility complex variation associated with juvenile survival and parasite resistance in a large unmanaged ungulate population (Ovis aries L.). Proc Natl Acad Sci USA 95:3714-3719

Payne R, Brazier O, Dorsey EM, Perkins JS, Rowntree VJ, Titus A (1983) External features in southern right whales (Eubalaena australis) and their use in identifying individuals. In: Payne R (ed) Communication and behavior of whales. Am Assoc Adv Sci Selected Symp 76, Westview Press, Boulder

Pettis HM, Rolland RM, Hamilton PK, Brault S, Knowlton AR, Kraus SD (2004) Visual health assessment of North Atlantic right whales (Eubalaena glacialis) using photographs. Can J Zool 82:8-19

Reeb D (2001) Structure, development and composition of the integument of the southern right whale, Eubalaena australis. PhD dissertation, University of Pretoria

Reeves RR, Rolland RM, Clapham PJ (eds) (2001) Causes of reproductive failure in North Atlantic right whales: new avenues of research. Ref Doc. 01-16, Northeast Fisheries Science Center, Woods Hole

Rowntree VJ, McGuiness PM, Marshall K, Payne R, Sironi M, Seger J (1998) Increased harassment of right whales (Eubalaena australis) by kelp gulls (Larus domincanus) at Peninsula Valdes, Argentina. Mar Mamm Sci 14:99-115 Schaeff CM, Kraus SD, Brown MW, Perkins JS, Payne R,

Editorial responsibility: Murray Dailey,

Sausalito, California, USA
White BN (1997) Comparison of genetic variability of North and South Atlantic right whales (Eubalaena), using DNA fingerprinting. Can J Zool 75:1073-1080

Smith AW, Skilling DE, Ridgeway S (1983) Calcivirusinduced vesicular disease in cetaceans and probable interspecies transmission. J Am Vet Med Assoc 183:1223-1225

Sokal RR, Rohlf FJ (1995) Biometry, 3rd edn. WH Freeman, New York

Thompson PM, Hammond PS (1992) The use of photography to monitor dermal disease in wild bottlenose dolphins (Tursiops truncatus). Ambio 21:135-137

Van Bressem MF, Van Waerebeek KV (1996) Epidemiology of poxvirus in small cetaceans from the eastern South Pacific. Mar Mamm Sci 12:371-382

Van Bressem MF, Van Waerebeek KV, Reyes JC, Dekegel D, Pastoret PP (1993) Evidence of poxvirus in dusky dolphins (Lagenorhynchus obscurus) and burmeister's porpoise (Phocoena spinipinis) from coastal Peru. J Wildl Dis 29: 109-113

Van Bressem MF, Van Waerebeek KV, Raga JA (1999) A review of virus infections of cetaceans and the potential impact of morbilliviruses, poxviruses and papillomaviruses on host population dynamics. Dis Aquat Org 38: 53-65

Van Bressem MF, Gaspar R, Aznar FJ (2003) Epidemiology of tattoo skin disease in bottlenose dolphins Tursiops truncatus from the Sado estuary, Portugal. Dis Aquat Org 56: 171-179

Waldick RC, Kraus S, Brown M, White BN (2002) Evaluating the effects of historic bottleneck events: an assessment of microsatellite variability in the endangered, North Atlantic right whale. Mol Ecol 11:2241-2249

Wilson B, Thompson PM, Hammond PS (1997) Skin lesions and physical deformities in bottlenose dolphins in the Moray Firth: population prevalence and age-sex differences. Ambio 26:243-247

Wilson B, Arnold H, Bearzi G, Fortuna CM and 12 others (1999) Epidermal disease in bottlenose dolphins: impacts of natural and anthropogenic factors. Proc R Soc Lond B 266:1077-1083

Wilson B, Grellier K, Hammond PS, Brown G, Thompson PM (2000) Changing occurrence of epidermal lesions in wild bottlenose dolphins. Mar Ecol Prog Ser 205:283-290

Submitted: April 15, 2005; Accepted: July 25, 2005

Proofs received from author(s): December 2, 2005 